\title{
Future of Remote Presence in Developing Countries and its Applications in Medicine (Robot to Otorob)
}

\author{
doi:10.3991/ijoe.v6i4.1400 \\ M. Iftikhar ${ }^{1}$ and M. Muralindran ${ }^{2}$ \\ ${ }^{1}$ School of Medicine, University Malaysia Sabah, Kota Kinabalu, Sabah, Malaysia \\ 2 School Engineering \& Information Technology, University Malaysia Sabah, Kota Kinabalu, Sabah, Malaysia
}

\begin{abstract}
Mobile robots are expensive for developing and under developed countries. Their utilizations are general in field of medicine, from neurosurgery to intensive care units. Our ongoing project “OTOROB” which stands for Orthopedic Robot is more specific for the usage of orthopedic surgeons with special consideration on its cost effectiveness. Statistical analysis of the survey conducted helped to identify the requirement of orthopedic surgeons to make OTOROB more specific. A new concept of VIrtual Presence (VIP) Specialist Clinic and Roboscope are discussed.
\end{abstract}

Index Terms-Medical Robots, Mobile robots, Remote Presence $\&$ Telemedicine

\section{INTRODUCTION}

Remote Presence (RP) is the ability to project yourself from one location to another (to be in two places at once) to move, see, hear and talk as though you were actually there [1]. Remote presence mobile robots are mainly concerned with the examination or video chatting with patients while doctor is away from them (RP-7 of InTouch Health Inc.). Its use in the field of medicine is popular in developed countries but its usage is unheard from developing or underdeveloped countries. "No news is a good news" not always stands true because it is required here too. Its price ranging from USD 100,000 to 150,000 is not affordable for many under-developed countries but it does not mean that this is not required here.

Applications of medical mobile robots are increasing from general ward to ICU and from general surgery or orthopaedic to neurosurgery. Our research project OTOROB (Oto; Malay equivalent of Ortho and Rob; is from Robot) is focused on affordability and its specificity for orthopaedic surgeons. Due to poor in infrastructure and availability of facilities especially in underdeveloped countries, shifting of patients from districts to state hospital and from island to mainland hospital takes about 6 to 8 hours which increases the rate of morbidity and mortality. The delay is further increased by wrong referrals. Most of the district hospitals are without orthopaedic surgeon and even state hospitals are overburdened. After tiring operations, surgeons sometimes receive a call from staff nurse or junior doctor regarding minor bleed or positioning of limbs after surgery etc. So he has to rush to the hospital just to confirm whether it is a massive bleed or a simple soakage \& limb positioning. The availability of RP medical robots will be greatly beneficial in these conditions.
In starting phase, a survey was conducted via telephonic or email for the orthopedic surgeons and medical officers/residents. They were requested to rate 10 Frequently Asked Questions (FAQ’S) from junior doctors (active on call) to surgeons (passive on call) or vice versa. The aim was to know the importance of additional tools (x-rays illumination system, BP \& pulse rate monitor, thermal sensor, pulse oximeter, Doppler ultrasound) for integration. This way the OTOROB becomes much more specific for orthopaedic surgeons. Here we also introduced the new concept of VIP (VIrtual Presence) or RP (Remote Presence) specialist clinics/hospitals along with ROBOSCOPE.

\section{AIMS \& OBJECTIVES}

The aim is for a cheaper (cost effectiveness) version of medical mobile robots for developing \& under developed countries without compromising concept of remote presence and its specificity for orthopaedic surgeons. Therefore it will help in reducing mortality and morbidity from orthopaedic emergencies.

\section{MATERIALS \& METHODS}

In first phase a survey was conducted (Feb, 2009 -Mar, 2009) for the doctors related to field of orthopaedics by a set criteria (Table 1 and 3) by dividing into them into two groups (specialist and non specialist). The survey was done either via telephonically or through email. Doctors were briefed before the survey (either one A4 page print material or 4 minutes telephonic introduction of mobile robots). To make the mobile robots more useful for orthopaedic surgeon, seven FAQ'S were established by experts and were given to them and three were left for their own discretion. The rating criteria are given in Table 2 and 4. Nine possible tools to be integrated in the project were given and their possible role in diagnoses was evaluated as in Table 5 and 6.

TABLE I.

CRITERIA FOR SELECTION OF DOCTORS FOR SURVEY

\begin{tabular}{|l|}
\hline 1. MO's currently working in orthopaedics at least for 2 years. \\
\hline $\begin{array}{l}\text { 2. Postgraduate residents have passed their part } 1 \text { of Master program } \\
\text { in orthopedics. }\end{array}$ \\
\hline $\begin{array}{l}\text { 3. All Specialists who have postgraduate degree recognized by min- } \\
\text { istry of health. }\end{array}$ \\
\hline
\end{tabular}


TABLE II.

RATING CITERIA FOR FAQ‘S

\begin{tabular}{|c|c|c|}
\hline Sr. & Significance & Rating \\
\hline 1 & Always & 5 \\
\hline 2 & Mostly & 4 \\
\hline 3 & Commonly & 3 \\
\hline 4 & Sometimes & 2 \\
\hline 5 & Rarely & 1 \\
\hline
\end{tabular}

Max Score $=$ No of doctors multiplied by 5 .

TABLE III.

DATA ON SURVEY

\begin{tabular}{|c|c|c|}
\hline $\begin{array}{c}\text { Over all response * } \\
\text { (40 in each group) }\end{array}$ & $\begin{array}{c}\text { E Mail } \\
\text { (20 each Group) }\end{array}$ & $\begin{array}{c}\text { Telephonic } \\
\text { (20 each Group) }\end{array}$ \\
\cline { 2 - 3 } & $\begin{array}{c}\text { Responded } \\
\text { DR's (No \& \%) }\end{array}$ & $\begin{array}{c}\text { Responded } \\
\text { DR's (No \& \% ) }\end{array}$ \\
\hline $\begin{array}{c}\text { MO's/Resident } \\
\text { 26(60\%) }\end{array}$ & $15(75 \%)$ & $11(55 \%)$ \\
\hline $\begin{array}{c}\text { Specialists } \\
\text { 32(80\%) }\end{array}$ & $17(85 \%)$ & $15(75 \%)$ \\
\hline
\end{tabular}

TABLE IV.

DATA ON FAQ'S

\begin{tabular}{|c|c|c|c|c|c|}
\hline & FAQ & $\begin{array}{r}\text { MOs } \\
\text { Ma } \\
26\end{array}$ & $\begin{array}{l}\text { Resident } \\
=26 \text { ) } \\
\text { Score : } \\
5=130\end{array}$ & $\begin{array}{r}\text { Spe } \\
(\mathbf{n} \\
\text { Max } \\
32^{*}\end{array}$ & $\begin{array}{l}\text { lists } \\
\text { 2) } \\
\text { ore : } \\
160\end{array}$ \\
\hline $\begin{array}{l}\mathbf{N} \\
\mathbf{o}\end{array}$ & $\begin{array}{c}\text { BASED ON } \\
\text { PRIORITIES }\end{array}$ & $\begin{array}{c}\text { No of } \\
\text { Drs. } \\
\text { Replied }\end{array}$ & $\begin{array}{l}\text { Score } \\
\& \%\end{array}$ & $\begin{array}{c}\text { No of } \\
\text { Drs. } \\
\text { Replied }\end{array}$ & $\begin{array}{l}\text { Score } \\
\& \% \\
\end{array}$ \\
\hline 1 & $\begin{array}{c}\text { Associated } \\
\text { injuries }\end{array}$ & 25 & $\begin{array}{c}125 \\
(96.15) \\
\end{array}$ & 32 & $\begin{array}{c}150 \\
(93.75) \\
\end{array}$ \\
\hline 2 & Open fractures & 25 & $\begin{array}{c}122 \\
(93.85)\end{array}$ & 32 & $\begin{array}{c}146 \\
(91.25) \\
\end{array}$ \\
\hline 3 & $\begin{array}{c}\text { Vascular inju- } \\
\text { ries }\end{array}$ & 24 & $\begin{array}{c}118 \\
(99.77)\end{array}$ & 30 & $\begin{array}{c}140 \\
(87.50)\end{array}$ \\
\hline 4 & $\begin{array}{c}\text { Compartment } \\
\text { syndrome }\end{array}$ & 26 & $\begin{array}{c}110 \\
(84.61)\end{array}$ & 36 & $\begin{array}{c}130 \\
(81.25)\end{array}$ \\
\hline 5 & $\begin{array}{c}\text { Fat/Pulmonary } \\
\text { embolism }\end{array}$ & 24 & $\begin{array}{c}100 \\
(76.92)\end{array}$ & 31 & $\begin{array}{c}128 \\
(80.00) \\
\end{array}$ \\
\hline 6 & $\begin{array}{c}\text { Unreduced } \\
\text { dislocations/\#'s }\end{array}$ & 26 & $90(69.23)$ & 32 & $\begin{array}{c}112 \\
(70.00) \\
\end{array}$ \\
\hline 7 & Spinal injuries & 23 & 87 (66.92) & 32 & $\begin{array}{c}110 \\
(68.75) \\
\end{array}$ \\
\hline $\begin{array}{l}8 \\
*\end{array}$ & Others & 26 & $* * * * *$ & $* * * * *$ & $* * * * *$ \\
\hline
\end{tabular}

* No 1-7 FAQ's were given in the survey and three columns were left empty for the discretion of doctors but none of the responded exceeded $50 \%$ of maximum score, therefore not described here.

TABLE $\mathrm{V}$.

TOOLS FOR INTEGRATION

\begin{tabular}{|c|c|}
\hline Sr. & Tolls Targeted For Integration In Mobile Robots \\
\hline 1 & Patient profile (age, sex, mechanism of injury etc) \\
\hline 2 & BP/Pulse digital monitoring \\
\hline 3 & X-rays illumination box \\
\hline 4 & High resolution camera to focus on person/wound \\
\hline 5 & Audio system(microphone) \\
\hline 6 & Thermal sensor to asses body/limbs temperature \\
\hline 7 & Doppler ultra sound to asses blood circulation \\
\hline 8 & Pulse oximeter \\
\hline 9 & Data storage \\
\hline
\end{tabular}

TABLE VI.

HOW MANY CASES YOU WILL BE ABLE TO DIAGNOSE BEING REMOTELY PRESENT SPECIALIST

\begin{tabular}{|c|c|c|c|}
\hline Sr. & No. of cases & $\begin{array}{c}\text { Specialist } \\
\text { (No) }\end{array}$ & $\begin{array}{c}\text { Specialist } \\
(\mathbf{\&})\end{array}$ \\
\hline 1 & $75 \%>$ & 2 & $6.25 \%$ \\
\hline 2 & $50-74 \%$ & 18 & $56.25 \%$ \\
\hline 3 & $25-49 \%$ & 8 & $25.00 \%$ \\
\hline 4 & $25 \%<$ & 4 & $12.50 \%$ \\
\hline
\end{tabular}

IV. RESULTS

Overall, 58 (72.5 \%) doctors from both groups (80) replied with an average of 3.2 reminders per person. Telephonic survey among junior doctors showed less interest (55\%) but a better response (75\%) was obtained through email probably because of the overburden work during office hours (so difficult to reply telephonic calls). Specialist response was better comparatively (Table 3). Question related to associate injuries (e.g. chest or head injuries) was No.1 whereas spinal trauma at position No.7 (Table 4). There was no significance difference in priorities by both groups. Patient profile and X-rays description are routine practice and therefore are not considered. Three questions were left for the discretion of the doctors but different answers were given and no one obtained above the $50 \%$ of the maximum score. When specialist were asked about the role of nine tools (Table 5) in the diagnosing process, more than $60 \%$ of the specialist were confident to reach at diagnosis at least in half of the cases (Table 6).

\section{DisCussions}

The Remote Work Vehicle (1986) was developed for a broad agenda of clean-up operations like washing contaminated surfaces, removing sediments, demolishing radiated structures, applying surface treatments, packaging and transporting materials [2]. The Ambler (1990) was a walking robot that enables energy-efficient overlapping gaits and developed as a test-bed for research in walking robots operating in rugged terrain [2-5]. Most of the currently available robotic system in orthopaedics are concerned with operation (surgery) but not related to pre or post op care. After long tiring operation; especially during off-hours surgeon receive a call from a ward nurse or junior doctor for minor issues that can be handled easily if surgeon had face to face dialogues. In these situations mobile robots are the solution. Intensivist participation in the ICU via telemedicine reduces cost and can render better care. It's known that if an intensivist is managing the patients in an ICU, the morbidity and mortality rates go down, the cost of care is less and the length of stay of the patient is shorter [6]. Thus, overall care is safer, better and more effective. To date, most research related to telemedicine has been limited to assessing the feasibility and effectiveness of remote medical education and cognitive consultation [7-10]. Telemedicine has been used by various specialties as a tool for collaboration between geographically isolated medical centers. In the surgical disciplines, telementoring, in which one physician is able to watch and "talk" with another physician through a surgical procedure has been successfully tested in a number of different venues [7-14]. In addition, remote management of ICUs by intensivists demonstrated shorter lengths of stay and lower 
costs when compared with units staffed by generalist physicians [15-16].

Dr. Neil Martin, professor and chief of neurosurgery at UCLA Medical Center (USA), believes that robots in future can be used to help man in emergency rooms where time is of the essence and immediate care is critical [6]. He says, "Telemedicine and virtual presence allow physicians who are not physically on site to avoid the time waste that's involved in traveling to the site of care" [1]. This new concept of Telerounding allows a physician to make virtual bedside visits from home, office, or any other location that offers broadband access to the Internet. The physician was totally dependent on the nurse's observations before but now the remote physician can drive the robot from bed to bed and have a real time, face-to-face discussion with the nurse at the bedside. It does extend their ability to make more rounds of a similar sort from their home or office. He can turn the head of the robot to look at the patient, the family or the nurse and have a twoway discussion as if he was standing there. All the kids whether they're your patients or not, want you to do rounds on them.

The technical training might take an hour [17]. Physicians are able to answer late night questions about the status of a postoperative patient without driving to the hospital and performing a personal examination [18]. That not only saves time, it relieves stress but designers need to consider two possibly dangerous failure modes: component failure and the possibility of a robot executing a correct command at the wrong place or time [19]. In orthopaedic, patient evaluation is based on history and physical examination (look, feel, move \& measure).With help of mobile robots history and look, move (active movements only), measure (apparent measurements only) can be judged but to feel, passive movements \& real measurements currently are not possible.

Robots are gaining acceptance in hospitals. At present, a fully functional medical robot includes components that emulate relevant human senses .The medical robot becomes the virtual eyes (seeing), ears (hearing), and mouth (speaking) of the person who controls it from remote location but clinically significant exception is the sense of touch and olfaction to some extent. A virtual nose (smelling) is also missing in medical robots, but smell is not a major clinical concern in the types of care supported by medical robots. A review of technical journals suggests that some engineers are working to add tactile capabilities to medical robots. Efforts to develop virtual olfactory extensions are not mentioned [20]. Sense of taste (gustatory) practically has no value in field of medicine. By adding vital sign monitoring apparatus, $\mathrm{x}$-rays illumination system, pulse oximeter and Doppler ultrasound, orthopedic surgeon will be able to diagnose about $60 \%$ of their cases. $\mathrm{X}$-rays boxes are not available on the bedside of all patients in underdeveloped countries as compared to modern countries. So, if it is not mounted on robot, we have to drive the robot every time to see the X-rays. Similarly without pulse oximeter \& Doppler ultrasound, the integrity of limbs circulation cannot be guaranteed. Thermal sensor will help us to know overall as well as comparative body response under different medical conditions especially in case of shock and cold extremities.
TABLE VII.

VIP SPECIALISTS

\begin{tabular}{|l|l|}
\hline Sr. & \multicolumn{1}{|c|}{ REQUIREMENTS FOR VIP SPECIALISTS } \\
\hline 1 & $\begin{array}{l}\text { Registered as specialist with medical council in his own } \\
\text { country }\end{array}$ \\
\hline 2 & Minimum experience of 5 years as specialist \\
\hline 3 & Mental well being \\
\hline 4 & Able to communicate through internet \\
\hline 5 & Preferably have some minor physical disability \\
\hline
\end{tabular}

Our target by making cheaper and more specific ortho robot (OTOROB) is to revolutionize this product by its availability to poor countries where specialist facilities are not up-to mark. Some experienced orthopaedic surgeons become less active because of aging, diseases, accidentally handicapped and sometimes not interested in surgery due to other reasons. But they are mentally active \& experienced. We can utilize their services (while they are staying at home) in VIP Clinics by establishing at national level through state and district level clinics linked with each other. Minimal requirement are given for specialist [Table 7]. Once the robots are available at district hospitals, it may be renamed as ROBOSCOPE like stethoscope, laparoscope, arthroscope or endoscope. Change of name will develop confidence among surgeons and patients because of commonly used word "scope' in field of medicine.

Inter-linking of these clinics to each other will make our world like a global village. It will be possible for remotely present physician to listen heart sounds while nurse is auscultating with stethoscope to screen the patient in different clinic from his main office with out driving. Similarly, assistant nurse will put the probe on patient and sonologist will give the expert report while enjoying a candle light dinner in hotel or by parking the car at road side once caught in traffic jam. Cardiologist can read ECG while the nurse takes care of patient. Radiologist can write expert CT scan / MRI report while technician is performing on it. Doppler scan can be visualized by orthopaedic surgeon immediately in case of vascular injury. Even two surgeons can discuss about their patient lively with virtual presence. It will also help in teaching rounds to the students. It is quite possible to establish Remote/Virtual Presence Specialist Clinic/Hospital (RP OR VIP SPECIALIST CLINICS/HOSPITALS) with the collaboration of developed countries for experimental and educational purposes in poor the countries to serve the ailing humanity.

\section{CONCLUSIONS}

Future of remote presence in developing countries is bright. With its more availability \& interlinking along with further innovation and research our world will become “Global Health Village”. Benefits of modernization will be available to them too by cost effectiveness. Consultation (but not replacement) of orthopaedic and trauma surgeons will be provided to them. 


\section{ACKNOWLEDGEMENT}

We would like to thanks all those doctors who spared their precious time for survey and suggestions \& our families for cooperation especially Mrs.Saima Masood.

\section{REFERENCES}

[1] Web of InTouch Health on www.intouchhealth.com

[2] Sankar S. Historical background \& design of robotics. Oct (2008); Article Base Free Online Directory

[3] http://www.robotics.utexas.edu/rrg/learn_more/history

[4] Satava RM. The early chronicles a personal historical perspective. WebSurg; Oct (2006):pp6-10.

[5] http://aurorian.blogspot.com/2008/02/world-we-live-in-is-com plex-place.html

[6] Neil Martin. Advanced Medicine, interviewed by Chelan David. Small Business Issue; March (2006).

[7] Whited JD, Hall RP, Foy ME, et al. Teledermatology's impact on time to intervention among referrals to dermatology consult service. Telemed J E Health (2002); 8:313-321. doi:10.1089/1530 $\underline{5620260353207}$

[8] Fieschi M. Information technology is changing the way society sees health care delivery. Int J Med Inf (2002); 66:85-93. doi:10.1016/S1386-5056(02)00040-0

[9] Maclean JR, Ritchie LD, Grant AM. Telemedicine: 'communication' by any other name? Br J Gen Pract (1997); 47:200-201.

[10] Dunn EV, Conrath DW, Bloor WG, Tranquada B. An evaluation of four telemedicine systems for primary care. Health Serv Res (1977); 12:19-29.

[11] http://www.robots.com/robot Education.php? Page= research history
[12] Grundy BL, Jones PK, and Lovitt A. Telemedicine in critical care: problems in design, implementation, and assessment. Crit Care Med (1982); 10:471-475. doi:10.1097/00003246-198207000$\underline{00014}$

[13] Nenov V, Klopp J. Remote analysis of physiological data from neurosurgical ICU patients. J Am Med Inform Assoc (1996); 3: 318-327.

[14] DormanT. Telecardiology and the intensive care unit. Crit Care Clin (2001); 17:293-301. doi:10.1016/S0749-0704(05)70168-8

[15] Celi LA, Hassan E, Marquardt C, et al. The eICU: it's not just telemedicine. Crit Care Med (2001); 29(8 Suppl): N183-189. doi:10.1097/00003246-200108001-00007

[16] Rosenfeld BA, Dorman T, Breslow MJ, et al. Intensive care unit elemedicine: Alternate paradigm for providing continuous intensivist are. Crit Care Med (2000); 28:3925-3931.7

[17] Web of the Robotic Institute on www.ri.emu.edu.com

[18] Rasmussen TJ. Dr Robot enhances patient interaction, Interviewed by Peter Pollack; Sept (2007) AAOS News.

[19] Paul Taylor. Will Robots Replace the Orthopaedic Surgeon? HBS Quarterly; August (2003): pp 6-8.

[20] Jeffrey C. Bauer. The future of medical robotics. TEWS White Paper May (2007)

\section{AUTHORS}

M. Iftikhar is with the School of Medicine, University Malaysia Sabah, Kota Kinabalu, Sabah, Malaysia

M. Muralindran is with the School Engineering \& Information Technology, University Malaysia Sabah, Kota Kinabalu, Sabah, Malaysia

Submitted July $7^{\text {th }}$, 2010. Published as resubmitted by the authors October $17^{\text {th }}, 2010$. 